\title{
Research Integrity in Scholarly Writing: A Global Perspective
}

\author{
Md. Amir Hossain ${ }^{1}$ \\ ${ }^{I}$ M. Phil. Research Scholar, Department of English, Jahangirnagar University, Bangladesh \\ E-mail: amir.hossain.16578@gmail.com
}

*Corresponding Author: Md. Amir Hossain, M. Phil. Research Scholar, Department of English, Jahangirnagar University, Bangladesh. E-mail: amir.hossain.16578@ gmail.com

\begin{abstract}
Integrity' is deeply related to honesty. In the literal meaning, there is no basic difference between integrity as well as honesty. Integrity is a noble virtue, without it, we cannot think of our existence, even we cannot proceed further to acquire any noble knowledge, or to fulfill any noble mission. But we sometimes fail to evaluate the true meaning and significance of the word, 'Integrity.' I think, we should practice it in our daily life so that we can realize and find out the reality of integrity in our real life circumstances. Otherwise, we will be victimized automatically. At the same time, we should bear in mind that truth shall come over today or tomorrow. So we should avoid dishonesty; and through honesty, we will have to lead our noble mission for any practical purposes. Then we will understand that real mission should never fail, we will be able to achieve integrity by honest criticism. In this research paper, I would like to express some viewpoints of mine regarding Research Integrity in Research Writing and/or Scholarly Writing, like any Research Proposal, Article Writing, Review Writing, Short Commentary, Conference or Seminar Paper, Monograph, Essay Writing, Thesis, Dissertation, Assignment, and Term Paper as well. When any research scholar plans to carry out a Scientific Research Project on any specific fields, what he has gathered experience and knowledge; he must have a pondering sense on integrity. Without it, he may not come out successful. Throughout the globe, there is a massive campaign regarding research integrity in the scholarly writing: Plagiarism free research writing should be our only motto. If there is no research integrity among the young research scholars, how can any supervisors or academicians expect a minute research project from them? In my opinion, the research scholars should have some honest targets while writing any types of research project, they should have practical sense of specific qualities as follows: research discipline, truthfulness and faithfulness, selfconfidence, nobility, integrity, patriotic feeling to research, gratefulness, devotion, research erudition, research methodology, publication ethics, liberal attitudes, professional encouragement, peer review, research acknowledgement, cooperation and friendship, research environment, references, innovation, new trends of research, motivation and inspiration, capability of spreading research knowledge, free and fair research knowledge, and so on. If the research scholars are enabled to acquire these noble qualities, they will surely establish a research integrity realm in the potential project. Anyway, Research Integrity should be our only expectation in Scholarly Writing.
\end{abstract}

Keywords: Integrity, Research Integrity, Scholarly Writing, Research Scholars, Young teachers, and Special Qualities.

\section{INTRODUCTION}

Scholarly Writing is one of the most potential and dynamic aspects of Research Methods. It broadens human thinking capability and it inspires a man discover new trends of cosmological epistemology in the field of universal science, arts and commerce. Scholarly writing is an original research project presenting thoughts and practical experiences in response to data found in library, internet, conference, seminar, and workshop at home and abroad. As a research scholar collects research materials, his ever increasing knowledge of a topic selection will allow him to get informed judgments and original interpretations. At each stage of a research project, a researcher will have a more complete knowledge of what he has already investigated and what he is now seeking.

The aim of this study is to inspire the research scholars and young teachers in research writing so that they can be able to broaden the free gate of scientific research project. Through this project, the

\footnotetext{
${ }^{1}$ To carry out this research project, the author has applied his own thoughts and practical experiences.
} 
current researcher tries to bridge all sorts of scholars, academicians, and researchers in a single community and circle around the globe so that they can be able to conduct a successful scientific project. They should have a slogan that there is no alternative means of scholarly writing. Young teachers and research scholars of the developing countries try to take pragmatic steps of research methodology so that they can be able to cope with the scholars of the developed countries. For this task, they must be studious and meditative attitudes to scientific research project and always they should be devoted to scholarly writing. In the competitive age, each and every teacher of the University level should inspire the students in scholarly writing and tries to organize seminar, symposium, conference, and round table talks every year. It is the duty and responsibility of the concerned authority of the University to train young teachers and novice researchers. Anyway, this scientific research project focuses upon research integrity in scholarly writing, importance of scientific research project; elaborate discussion of scholarly writing; basic qualities of scholarly writing; scholarly writing in the global perspectives; significance of the current project, and recommendations.

\section{AIMS AND OBJECTIVES OF THE STUDY}

This study aims to look at research integrity related to scholarly writing. Research scholars should have honest aim and target. If they don't have any integrity while carrying out a scholarly research project, they can never come out successful in the field of research. In this regard, what their aims and objectives should be are as follows:

To have a deeper understanding of research knowledge;

To maintain research integrity while they hit upon a plan to start a new project;

To try to find out potential research field;

To keep aloof themselves from plagiarism;

$>$ To practice research methodology and research writing with integrity;

To follow noble qualities of scholarly writing;

Try to explore and investigate scientific research project;

$>$ To carry out a scholarly project through applying the theory of Epistemology;

Try to carry out a research project in the $21^{\text {st }}$ - century global perspectives;

To have devoted mentality and sensibility.

\section{RESEARCH QUESTIONS}

In this potential research project, I have tried heart and soul to answer the following questions with a view to focusing upon research integrity in Scholarly Writing. If any research scholar fails to maintain research integrity, he cannot come out successful in carrying out a potential research project. In this regard, some specific questions are as follows:

1. To what extend does Research Integrity impact upon the mind of research scholars?

2. What sorts of complexities do they have to face if they follow plagiarized means?

3. What sorts of qualities do research scholars follow?

4. To what extends can honest Scholarly Writing bring for them?

5. How does scholarly writing of developing countries differ from European Research?

\section{INTEGRITY}

Integrity is a noble virtue. In human life the essence of integrity is much more. It cannot be measured or described with general ideas and concepts. To the people of each religion, it is a rare quality; without it, they cannot progress in life. It cannot be purchased by finance or pelf and power. A man can achieve this quality through his honest character and nobility. There is no difference between the rich and the poor to acquire integrity. All are equal in the eye of integrity.

There are many people living in society and community who are poor and rich. Some of them earn money in an honest way, and others earn money in an unfair way. Though they prosper in life; they have much property and finance, but in the long run, nobody sheds tear for them; after their death, they will be forgotten. But if a man is able to acquire integrity, he will be honoured and respected in 
society during his life time and even after death. There are many persons on earth who have become great and famous because of integrity and nobility. In this regard, we can mention of our great Prophet Hazrat Mohammad (Sm.). He was a true preacher of Islam; he was devoted to integrity, nobility, faithfulness, just, kindness, and the direct commandment of Almighty Creator from his birth to death.

In English literature, many litterateurs have written novel, fiction, nonfiction, story, and treatise regarding integrity. Integrity has occupied a prominent place in English literature. An example may be cited in this regard: Marjorie Kennan Rawlings' "A Mother in Manville." Through the character of Jerry, the authoress wanted to emphasize upon honesty; and regarding Jerry's honesty, she comments: "It is embedded on courage, but it is more than brave. It is honest, but it is more than honesty." ("A Mother in Manville", 8) Jerry broke the axe handle one day, and then he said that the workshop at the orphanage would repair it, he brought the money to pay for the job and he refused to take the money from the authoress. In this way Kennan presents Jerry's character to us with a view to fostering integrity.

Again if we look at historical facts, we will learn that many heroes have sacrificed their lives for the greater welfare of the country and the nations. Siraj ud-Daulah was a true patriot; a true lover of his countrymen. He never surrendered to injustice; he protested against the British and injustice. His own relatives and family members conspired against him. Mir Jafar was the main conspirator of Nawab. But he was brave, noble, honest and faithful.

Moreover, in philosophy we can see many examples of integrity. Many wisest philosophers were great and honest. Socrates, Aristotle, and Plato were the wisest philosophers for all times and for all ages. Socrates was a believer of truth; he was preaching truth of his times among the younger generations. Many of them were influenced by him, and they began to follow the truth path of life, but the then rulers did not take it very easily, he conspired against Socrates; an impeachment was brought against him, he was given to drink hemlock. He drank it and before dying, he said: "I to die, you to live." He was an honest philosopher; he never surrendered himself to injustice. He realized firmly of truth and honesty of his times. Anyway, there are many and lots of incidences on earth concerning honesty, which we cannot describe in words. We should bear in mind a famous maxim: "Honesty is the best policy."

\section{RESEARCH INTEGRITY}

Research integrity is a very complex issue for academicians, young teachers, novice researchers, and scholars around the globe. To get University promotion, to develop professional career, to go to abroad for higher studies and so on, research integrity is a must for researchers. If they violate research norms, principles and codes, they can never come out successful to carry out a successful research project. Every research scholar and young teacher ought to abide by the rules and regulations of research integrity. When a scholar plans to conduct a potential research project, he must try heart and soul to apply own knowledge and epistemological sense with a view to developing his creative sense.

Research integrity deals with the utilization of honest and verifiable approaches in suggesting, performing, and considering potential research-work, reporting research outputs with special attention to adherence to rules, regulations, submission guidelines, ethics, and maintaining commonly accepted professional codes and principles. Research integrity means as a strong adherence to the ethical norms and professional standards essential for the responsible practice of potential research project. By strong adherence, we mean an adoption of the principles and practices as an individual credo, not regarding them as expositions by the rule-makers of potential research. By ethical principles, we mean integrity, potential rule, faithfulness, and standard regard for the scientific record of a potential research.

Research integrity is the benchmark of potential research project. Without it, the complicated interweave of the delicate fabric i.e. potential research starts falling apart in unexpected and undesirable means. To advance and innovate personally and as a community and a society, we depend vigorously on the delicate bond of faith and integrity that remains between research scholars and supervisors, as the members of the greater scientific research potential community.

NAS report definition: "For individuals research integrity is an aspect of moral character and experience. It involves above all a commitment to intellectual honesty and personal responsibility for 
ones actions and to a range of practices that characterize responsible research conduct." (Steneck, p.

3) These practices may be mentioned as follows:

$>$ Honesty and fairness in proposing, performing, and reporting research;

Accuracy and fairness in presenting contributions to research proposals and reports;

$>$ Proficiency and fairness in peer review process;

$>$ Collegiality in scientific interactions, communications, and sharing of resources;

$>$ Disclosure of conflicts of interest;

Protection of human subjects in the conduct of research;

Adherence to the mutual understanding of supervisors and research scholars.

While science and technology motivate powerful defense of a researcher's thoughts and task, genuinely research integrity means investigating the data and information with objectivity and being regulated by the outputs rather than by pre-conceivable issues.

In this study, we would look at some main issues of which we ought to be conscious as an apprentice in the greater scientific potential research community. Our aim is not to let a research scholar what to imagine, what to do, or to provide him with any magical dictum for concluding a decision concerning right and wrong in any circumstance. We should swiftly observe that the landscape in potential research by dint of its un-investigated and unimaginative nature is fraught with complex, multifaceted issues. Such issues require ideas and need to be re-examined as potential data are found. We see that prior experience, family, society, culture, community, and religious faith lead us to sometimes a consensus with our peers, but at other times to different comments than those around us. As a result, the issue is to equip us to think out first, ask second, and act third when faced with innovative, unfamiliar, and often complex thoughts, ideas, and circumstances. These enable us to sidestep problems; when practical, make sage decision; when challenges arise, and in the long term adjust us to act with ethical leadership when called upon to adjudicate the hard challenges of postmodern research project with wisdom, intelligence, compassion, and personal research integrity in light of practical field of potential research project.

\section{IMPORTANCE OF RESEARCH INTEGRITY}

Scientific investigation is based upon a surer foundation of faith. Scholars think that potential research outputs are an honest and perfect index of a researcher's potential project.

Professional researchers have a special duty and responsibility in highlighting and promulgating high standard of potential research project in science, literature, and language. They should serve as role models for the novice researchers and for their colleagues, and they should exemplify responsible practices in teaching and conversing with others. They have a professional obligation to create positive research milieu and to respond to concerns about irresponsible behaviours. Professional researchers can themselves gain a new appreciation for the importance of professional standards by thinking about the topics presented in the guideline and by discussing those topics with the research circles and communities. Thus, they help to maintain the foundations of the scientific research project and its reputation with educational institutions and beyond.

Research integrity is the commitment- in the wake of adversity- to the faithfulness of the research approaches by the greater scientific research project community. It is very essential, even critical, because the greater scientific potential research community can innovate and refresh when its members function together as a body to ensure a climate that enhances self- confidence and belief in potential research findings, inspires free and fair exchange of research sources and new plans, ideas, highlights individual and corporate accountability, and acknowledges and respects the intellectual contributions of other research circles in the greater scientific potential research community.

From above discussion, it is found that it the 21st - century age, young teachers and novice researchers must follow the rules, regulations, submission guidelines, publication policy and ethics, while they decide to publish any scholarly writing in any journals, or submit thesis and scholarly work for kind evaluation at any educational institutions around the globe. If they fail to do so, their academic degree will be rejected and for this they may have to fall victim of academic crime seriously. 


\section{SCHOLARLY WRITING}

Research is deemed as diligent and methodological investigation into a subject with a view to finding out or revising reasons, theories, and applications. Writing is explained in the original form as the act of a person or thing that wants to writes or to compose. Research is carried out in much systematic way and does not have to be academic naturally.

Scholarly writing comes from a researcher's wit and knowledge in which he is devoted. He tries utmost to develop his research writing until he comes out successful. Scholarly writing ought to be emerged from a practical merit of any scholar. To write a scholarly project, he writes to apply the theoretical knowledge, like literature, linguistics, social sciences, engineering, medical science, and so on. He should have meditative mood, honest target, and perfect mind so that he can be able to carry out a pure research project independently. For this he wouldn't rely upon anybody, rather he continues his efforts to accomplish the project. Like a scientist, he tries to prove his formulae; he would explore and investigate something new and potential with the demand of the age. He would never lag behind from his real motive until he fulfills his strong desire. A scholar must fight for carrying out his scholarly project like a scientist.

Scholarly Writing is a very complex issue. Nobody can write any scholarly topic if he has not any previous experience and at the same time, he must have a proper knowledge of research methodology. He may have a vast experience on any specific area, but he if he does not have any experience on methodology, he cannot write any research proposal despite this strong desire. For instance, to write a scholarly paper, a research scholar has to choose a potential topic, carry out a research project and articulate logic in a methodological way. Scholarly Writing can be long or short, and they are embedded on a thesis statement. The complex portion is to prepare an outline of the whole research project to systematize his arguments and skill of research knowledge. It is important to cite any kind of sources. There must have research integrity in the scholarly writing. If he fails to properly mention any sources, he has to face an academic punishment, which is deemed as plagiarism with the writing and calls into the questions of an academic honesty.

A scholarly writing varies from others' writing when anyone is asked to do so, in that it makes him to investigate sources beyond his concepts. This requires a research scholar, such as conscious reading and understanding of the sources and proper citation style. But it lets a scholar enjoy opportunities and benefits. In a scholarly writing, a research person has to marshal data or logic from others' materials which sharpen mechanisms in a very impressive way. This technique also allows him to place his argument within a right formula for identifying research knowledge.

To write a research project means that a research scholar must select a topic and then, ponder upon a hidden idea that he wishes to realize the topic to narrow it down, which is considered as a thesis statement. His thesis fixes where he goes from there and invents what type of research project he wants to carry out in order to advocate his own project in a proper way. He presents his own argument alongside his findings in a research project that highlights what he has concluded as a result of studying the specific topic he did select before. A scholarly writing must contain a works cited page, which lists the sources through using MLA, APA, Chicago citation style, and so on.

Scholarly writing has to produce a scholarly project based upon research field that a scholar research wants to carry out. Depending on the specific field of the project and the specific requirements of the project, scholarly writing may or may not be empirical, quantitative or qualitative research project.

The reason as stated above, it is proved that scholarly writing is certainly a very sensitive case. A researcher must have a deep knowledge; he must study what he plans to carry out his project. Another important thing may be mentioned in this regard, he must think long before he starts project writing. He must consult with any literary or language experts, and must express his plan very clearly. Then, he tries to combine both ideas and knowledge what he has gathered experience.

There are several types of scholarly writing. They are research proposal, article, seminar paper, symposium paper, conference paper, thesis, dissertation, assignment, essay, term paper, treatise, and so on. The research scholar has to concentrate his full-attention to focus on scholarly writing in a very logical, organizing, and methodological way so that he can present himself in front of everybody. Scholarly writing may be published or unpublished. 
Scholarly writing fully depends upon the requirements of the institution, research organization, or guidelines of article submission around the world. Scholarly writing may be personal or impersonal of the researcher. In fact, it is practiced based on any specific project.

What I would like to present here for any research researcher, is to practice scholarly writing in such way that it totally gets rid of plagiarized writing. As a teacher or a researcher, we should bear in mind that there is a campaign around the globe: Plagiarized writing must be protected at any cost, it might give a researcher an academic punishment since it is an academic crime. For this, he may be repelled from his post if he fails to acknowledge honestly from where he has taken his sources. A research scholar ought to concentrate his attention upon scholarly writing; he may have an outstanding academic background, but, if he does not have any idea upon research methodology, he cannot come out successful. A scholarly writing can give a research scholar scholarship, funding support to carry out a research project at home and abroad. Moreover, scholarly writing can provided for him teaching promotion and potential career opportunities around the world.

\section{SPecial Qualities of SChOlarly Writing}

Researchers should follow some special qualities while they are devoted themselves to scholarly writing. If they fail to acquire noble qualities, they would not come out successful in carrying out a research project on any braches of epistemology, like science, commerce and humanities. If any scholarly writing does deal with honesty, it does not beautify and signify itself. It will automatically lose its inner truth and beauty. In this regard, I can mention a famous line of John Keats's Endymion: "A thing of beauty is joy forever." What I mean through this sentence is that scholarly writing must have a beauty and integrity. Then it will be a perfect aspect of research methodology.

Scholarly writing and noble virtues are interlinked each other. Researchers try to bridge a research realm between them. We remember in mind that without noble virtues, man cannot shine and go ahead in life; many people on earth have become great and well-reputed due to having noble qualities. If there is no any noble virtue among research scholars, they hardly carry out a potential research project. Anyway, in my opinion, research scholars ought to practice some noble virtues, when they keep their full-attention to scholarly writing. They are as follows:

\subsection{Research Discipline}

If any research scholar does not have a research discipline, he cannot taste and touch of a real scholarly writing. He must try to maintain research integrity with dignity and industry. He should be time keeper, devoted scholar, cordial and friendly manner, and disciplinarian in his path. He must maintain regularity with a time framework. Suppose, a PhD Research scholar must complete his research project within a stipulated time, otherwise, if he fails to do so, his research degree may not be awarded in a scheduled time. His research discipline must be honest and perfect in carrying out a potential research project. Especially, in the developing countries of the world, including Bangladesh without having research discipline, researchers have to suffer untold sufferings, it take more than 8 years to complete M. Phil. and PhD Research Project due to inattention of supervisors and externals. Without having research discipline between supervisor and young researcher, to get the degree is an uncertain concern.

\subsection{Truthfulness and Faithfulness}

Research Scholars should gather experience of truthfulness and faithfulness if they want to become practical researchers. Without having truthfulness and faithfulness, nobody can come out successful in life, if they succeed, it cannot last long, just for the time being, they are honoured and respected. But after their death, nobody come to mourn for them; they will get mixed in the sea of dust; even some of them blame them for dishonesty. In our current society, there are many people who earn money in an unfair means. The case is the same for research scholars. Now it is found that many researchers try to copy, cut, and paste others' comments directly from the internet sources, books, journals, and reference sources without any acknowledgement and citation in doing their own research project. The main reason is that research scholars have failed to realize the inner meaning of truthfulness and faithfulness. Anyway, they must grasp the roots of such noble qualities in carrying out their own project. 


\subsection{Self-Confidence}

Self-confidence is a great virtue of human life. There are ups and downs in a man's life. There is a proverb: "Make hay while the sun shines". We should not get afraid, when we see a black cloud in the sky. Rather we should remember in mind that better day will come again. If any research scholar has self-confidence, he must succeed inevitably in the long run. Scholarly writing is obviously a complex task, he cannot express or think what he wishes in a general sense, and rather he must have research knowledge and methodology in an organizing way; and he tries to apply his practical wisdom in his own research project while he makes himself busy in his own expertise. So an important aspect of scholarly writing is self-confidence, which researchers must have achieved by hook or by crook.

\subsection{Nobility}

Nobility is a great virtue. Nobody can deny the fact. Without it, a man cannot be successful; he must till nobility from the very beginning of his life. Nobility makes a man great and famous. Similarly, a research scholar must have achieved nobility. If he does not have a noble mind, he cannot carry out his scholarly writing in a surer foundation. If the seed of nobility is deeply rooted in scholarly writing, it must attract the attention of supervisors, academicians, colleagues, and researchers around the world. Thus his reputation spreads throughout the world. Noam Chomsky's noble scholarly writing is a glaring example of research field around the globe. Moreover, those who deserve for Emeritus Professors at the University Level, have ample nobility of research writing. In the 21 st - century age, young research scholars should follow the examples of noble persons, who are the David in deed.

\subsection{Integrity}

Though the word, 'integrity' is related to nobility very closely, but in this research project, I would like to emphasize upon integrity in the light of scholarly writing. Integrity is embedded upon courage; it is honesty, but it is more than that. In the literary realm, there is much more examples of Integrity. Such as the integrity of Hazrat Mohammad (Sm.) is known to all. From the birth to death, the great Prophet has tried to preach the essence of integrity among all communities in all his endeavours. Here I don't want to elaborate the matter, since my plan is to germinate the seed of integrity in scholarly writing. What I try to make the research scholar understand is to follow whole heartedly the research integrity while they ponder over scholarly research project. Without attaining integrity, no research scholar can realize the inner significance of scholarly writing. Therefore, researchers must practice integrity while they hit upon a plan to do a potential research project.

\subsection{Patriotic Feeling to Research}

Research scholars must have a patriotic feeling like a true patriot. A true patriot is he who loves his motherland more than his life on earth. He never hesitates to sacrifice his own life for the greater welfare of the country even though he knows that his death is inevitable in the battle field. For example, in the Liberation War-1971 of Bangladesh many soldiers, civilians and innocent figures and intellectuals have sacrificed their lives for the protection of the homeland. Now they are remembered and recorded in our history to mark their noble deeds so that the younger generation can pay due respect to them. Similarly, today's your research scholars ought to follow the footprints of the patriots. We have many patriotic records, writings, and history; so we should focus our full-attention upon them through scholarly writing. What I want to let you know is to have patriotic feelings of the novice researchers to research writing.

\subsection{Gratefulness}

Gratefulness is related to magnanimousness in the literary sense. If any scholarly writing does not have gratefulness, it will lose its true identity of research. In this regard, research scholars must have experience of gratefulness if they are not grateful to research, nobody can understand the mystery of his project; and nobody can get benefit from his hard earned scholarly project. Here I want to clarify the matter through giving an example: While carrying out a potential research project, a research scholar needs someone's help to collect information, data, primary and secondary sources to strengthen his own ideas and thoughts logically. Otherwise, he cannot complete his project successfully. Suppose, after completing the research project if any research scholar fails to express his gratitude to the helpful persons, or he is not grateful to useful persons from who he once collected data, but now he totally has forgotten his contribution. I think, a grateful research scholar must abandon selfishness in carrying out a scholarly research project. 


\subsection{Devotion}

It is very difficult to ascertain the right measurement of 'Devotion' through my immature sense. Only the religious figures can realize the inner essence of Devotion. Again those who have direct communion with Almighty or the Mystery of the Universe can figure out the analysis of devotion. If the term 'Devotion' is properly applied to scientific research, I sense that scientists, scholars, doctors, engineers, literary \& linguistic votary would understand the depth of devotion in the very core philosophy of life. A practical mined research scholar perhaps may enable to measure the balance of the term 'Devotion' with his integrity and courage. Devoted research scholars can find out the real value of devotion when he get himself engaged into scholarly writing. The investigation of devotion as well as scholarly writing is complex and it is like a scientific truth. Anyway, a research scholar should be devoted figure while he would like to investigate something new in his field what he is seeking.

\subsection{Research Erudition}

Without acquiring research knowledge, anybody cannot be a research scholar. If he wants to become a research scholar conversantly, he must ponder himself upon research writing. To understand the theory of "Epistemology," the wisest philosophers and scientists of the world have worked hard throughout their lives without taking any rest. Research knowledge is an unlimited branch of Epistemology like the mystery of the cosmic. Research is the store house of knowledge; nobody can quit the research erudition. In this regard, I can quote some immortal lines of Rabindranath Tagore:

I have travelled for many days, over many miles

Having spent a lot of money travelling around many countries

Went to see the mountains, went to see the Indus

I missed out looking at a small droplet of dew on a paddy leaf

Just two steps away from my home....[Visit: Bystander's outlook: Some immortal lines from

Rabindranath Tagore]

Scholarly writing is like a small droplet of dew on a paddy leaf. It is an unending journey in a scholar's life. His life is transient on earth, but Epistemology is ever lasting formulae. If a research scholar is able to taste the experience of Epistemological Research, he wouldn't have a time of taking a single rest.

\subsection{Research Methodology}

A research scholar must have a proper knowledge of research methodology; he must investigate the theory of research; he continues to do so. On the contrary, if he doesn't have a profundity of research methodology, he won't be able to find out the basic skills of theoretical research. In the postmodern age, it is seen that most of the scholars and supervisor prefer theoretical research to thematic research in the light of very recent times. They want to compare and contrast the remote truth with the current truth with curiosity and impression. Suppose, many literary scientists are devoted to find out Aristotelian Dramaturgy/Formulae; and at the same time they want to investigate Aristotelian Oeuvre through making a comparison between Aristotle and Shakespeare. What I would like to present a logic is that a research scholar can never determine the Dramaturgy between the two legendary figures if he doesn't have a minute knowledge of research methodology.

\subsection{Mobility of Research}

If a research scholar doesn't have a mobility of scholarly writing, it would be very difficult for him to carry out his research project in time. Many researchers are not careful of their project, they want to put off their work for tomorrow; they don't try to understand the fact if the project is not done in a scheduled period, they will begin to forget the previous idea what they did investigate before. Just think that if a research scholar does stop his research project, or he doesn't practice article writing for five years, will it be possible for him to complete the whole project in accordance with the mobility of research? Mobility of research sharpens the memory of the scholars; it increases their research knowledge. In fact, it is like a continual process or Time like an old gipsy man.

\subsection{Publication Rules}

Research scholars ought to maintain publication policies and ethics while they decide to publish any scholarly writing. Researchers must follow submission and authors guidelines for publication process; 
many don't want to follow the journal's rules and regulations due to their limited knowledge of research methodology. As we generally know that each and every journal has to maintain specific style, like APA, MLA, and Chicago Manual Style. Scholars may not be expert of these styles. For this they have to study a lot upon the style so that they can be able to publish an appropriate scholarly writing and high quality of research paper for which they can apply for bursary, funding support or scholarship at home and abroad. To get a scholarship is very highly competitive at a foreign university in the potential research project. If they fail to maintain publication ethics and policies properly, they may not expect scholarship.

\subsection{Liberal Attitudes}

Research scholars must have liberal attitudes to any kind of scholarly writing. If they narrow their ideas down, they can never hope for a bright scholar. They have to be free thinker and liberal minded in carrying out a potential research project, the reason is that they have to consult with the right person whom they regard deserving. Without feeling any hesitation, they can contact and discuss with the persons with a view to collecting necessary information for the project what they are investigating. Without having liberal attitudes in any scholarly writing, researchers cannot focus their ideas and thoughts upon the project. So liberal attitude is a must for scholarly writing. Many researchers don't want to share person opinion with an unknown person; they feel shame; they think if they share personal matter with him, he may take it other hand.

\subsection{Professional Encouragement}

Scholarly writing makes a research scholar encourage in his professional career. To develop the professional career, research scholar must take a strict decision since the age is very competitive and innovative. Without research publication in any impact factor or standard journal, a researcher cannot expect promotion or increment at his teaching arena. Many academicians think that International Publication has a high quality value than nation publication. On the contrary, in Bangladesh, teachers of public universities don't appreciate International Publication, in this regard, the reason which I think that they are not expert in internet search or online version; they have a silly notion about online version, but now the young research scholars are very much updated; they are deviated from their teachers' outworn idea. Many of them try to publish their research papers in International Journals. Another problem is that there is no easy way to pay publication fee because we have no PayPal or Credit Card system. Anyway, we do hope that very soon we would enjoy the postmodern online system; it is not very far.

\subsection{Peer Review}

Research scholars must have honesty in peer review process. If they don't have research integrity in review process, or they fail to maintain publication policy and ethics, scholarly writing will lose its original identity itself. What I would like to emphasize upon the clue is that peer review process must contain in scholarly writing; research scholar also must maintain peer review quality with honesty and respect if he wants to familiarize himself with other culture and community around the world. We know that peer review is a basic demand of any scholarly journal when any scholar wants to publish a scholarly writing, he wants to know the fact whether the journal is peer review or not. Without having peer review process, no characteristics of any journal can be expressed. Therefore, research scholar must have respective sense to peer review journal.

\subsection{Research Acknowledgement}

Any research scholar cannot expect a high quality research paper if he does not acknowledge properly, otherwise such a paper will be regarded as plagiarized writing in accordance with the institutional norms and publication ethics. He must cite from where he has taken his necessary sources in the whole project through following research methodology. If he fails to do so, his potential research degree may not be awarded by the academic council. It is found that many researchers don't know how to acknowledge, how to write foot and end notes, how to cite and how to prepare bibliography. They just paste, cut, and copy from the internet sources with any acknowledgement. But their papers are experimented and checked by the plagiarism software checker, the similarity report indicates that the project which the researcher has plagiarized without any citation and acknowledgement, shows the whole pasting options are marked with different colours from where he has taken his sources. Here I want to strengthen my viewpoint that all research scholars must acknowledge his scholarly writing with citation. 


\subsection{Cooperation and Cordiality}

Cooperation as well as cordiality is the important aspect of scholarly writing for any research scholar. If he fails to maintain these qualities, he can never be a great scholar. If any novice researcher needs help from an experienced researcher, he must cooperate with him and tries to make a close cordial relation with him. It does not mean that a novice researcher will steal his cherished research knowledge, rather both of their research knowledge will increase in the realm of epistemology, and they will be benefitted each other. Cooperation as well as cordiality is a noble virtue in a man's life. Without this quality, nobody can foster his dormant quality or hidden treasure. He must cope with others in a balance and an equal manner. Similarly, a research scholar must have cooperation and cordiality with his fellows if he wants to develop his scholarly writing.

\subsection{Research Environment}

To beautify and signify scholarly writing, a research scholar must build up a research environment. Scholarly writing much depend upon its milieu; and a researcher must try to create his environment beautifully in order that he can be able to cope with his competitors in the contest. He should remember in mind that the $21 \mathrm{st}$ - century is a scientific competition age. Without competition, nobody can exist. If he wants to make himself fit for an adroit research scholar in the realm of knowledge, he must fight continuously to germinate a seed of scholarly writing. He must have a practical mentality and sensibility to create a research environment. We have seen that many philosophers, scientists, researchers, scholars, poets, dramatists, novelists, and many more were born in a very lower class family, but they never lag behind from their real motive, sometimes most of them fall victim of poverty, financial constraints and psychological conflicts, with the environment and circumstance, they have enabled to tackle; and they have enabled to set up an environment in their respective mediation.

\subsection{References}

If any research scholar fails to mention reference lists properly in the research project, or he fails to acknowledge citation as well as in-text citation, his project may be regarded as plagiarism. As we generally know that a scholar may collect his material if he thinks that his collected sources are very much important for his own project. In that purpose, he would borrow them, but he must mention to the point through following the rules and norms of research methodology. References or bibliography must be mentioned at the end of the project; at this point some follow MLA, APA, or Chicago Manual Style as per instructions of institutions. Therefore, a research scholar must have outstanding knowledge how to cite, quote, and to write documentation. To write such things, he must maintain research integrity; otherwise his academic hard earned degree or his position may be rejected. Even he is punished for violating such academic crime.

\subsection{Innovation of Research}

Research writing is an innovative quality for the research scholars. Every scholar wants to foster a new and potential research project so that he can be able to utilize the project in a scientific manner. Research means to apply the theory of epistemology for his potential research project, where he will be able to invent a new aspect of research methodology through his cognitive knowledge, practical experience, and expedient thoughts. The aim of a research scholar as well as a literary scientist is equal for the respective project, where both of them are meditated to investigate and find out a new formula that we can apply for the realm of erudition. The aim of a scientist is to experiment and explore science with his cognitive sense, which is greater welfare for the scientific and technological development. Similarly, a literary research scholar aims to look at the potentiality of the innovative project for which novice researchers can be able to acquire new knowledge and research methodology. Now it is seen that both a literary scholar and a practical scientist are devoted to literature and science respectively with a view to carrying out an innovation of scientific research project.

\subsection{Motivation for Scholarly Writing}

Motivation as well as inspiration is closely related to scholarly writing. If any research scholar does not have motivational skill, he cannot be a good researcher. Motivation for the young researchers is an essential aspect of scholarly research project. Due to the lack of motivation, many research scholars cannot carry out their project, though they start earlier, but later it is found that they lose their mental 
support. The reason may be either of their own or of the supervisor's inattention. Many a tine again it is seen that there is a contradictory attitude between a research scholar and a mentor regarding the project. In such case, the researcher fails to satisfy the demand of his supervisor how the project should be or what he expects from the researcher. What I mean to realize that there must have a motivation for scholarly writing between the research scholar and the supervisor.

\subsection{Capability of Spreading Research Knowledge}

I think that a research scholar should have capability at which process the research knowledge can be spread in his own domain. He must try to find out new findings and potentiality of scholarly writing in such a way that he can be able to foster a new project in the light of a very recent time. Though it is a very complex issue to plan a scientific research methodology, a scholar never hesitates to try for analysis as well as investigation of his project in order that his contemporary researchers can be able to get something new. He tries heart and soul to make himself a deserving scholar of his times through his honest industry and deep devotion. In this regard, I can mention the famous statement of Albert Szent Gyorgyi: Research is to see what everybody else has seen, and to think what nobody else has thought.

\subsection{Free and Fair Research Knowledge}

Research scholar must have free and fair research knowledge skill when they plan to carry out a research project. If they are able to come up with a free and fair scholarly writing, their reputation and popularity will be on the increase among their colleagues. They can increase their literary maturity through practicing scholarly writing. In the $21 \mathrm{st-century} \mathrm{age,} \mathrm{researchers} \mathrm{are} \mathrm{not} \mathrm{interested} \mathrm{in}$ traditional research knowledge, they want to bring out a significant change in the field of literary genres. They are very much conscious of new trends and potentiality of scholarly writing instead of old trends. They ought to be free and fair minded to carry out a potential research project. If they don't have free and fair mentality, they cannot complete a free and fair scholarly research project. Free and fair research knowledge is essential for any scholarly writing. And, to do this task, research scholars must be dedicative and creative.

From the above discussion, we can say that research scholars should follow special qualities as mentioned above while they would decide to undertake a scholarly research project. They should have honest aim when they plan to carry out a research project.

\section{Scholarly Writing in The Global Perspectives}

Global Perspectives determines academic expertise in a practical context, being a seminar-based opportunity to investigate a wide range of issues challenging people around the globe. Enhancing critical, analytical research project and problem-identifying skills important to higher studies, young teachers and novice researchers will learn to apply their own thoughts and ideas in the global perspectives, finding new inspirations and challenges for innovative research skills and knowledge. Scholarly writing in the global perspectives has undoubtedly a much value for the young teachers and novice researchers. They can bring about a significant change for the development of Education System of a country if they are properly well-conversant with practical research knowledge. They can't imagine of their existence without research. A quality of a standard education of a country can be broadened throughout scholarly writing around the globe. Nobody can easily measure the profundity of scholarly writing; its depth is unlimited and uncounted in words, or even in language. Of course, scholarly writing should be original and it is a complex issue for researchers.

Scholarly writing in the light of Asian countries, including Bangladesh, is now being practiced by the young teachers and novice research scholars for their academic purpose and the development of professional career. Some of the University teachers here in Bangladesh are very much interested to conduct a scholarly project for higher studies at home and abroad with scholarship as well as funding support. But they have no proper knowledge of research methodology though they have vast knowledge of books what they have read and learnt at the tertiary level of Bangladesh educational institutions. They don't get ample opportunity to develop the scholarly writing skill. There are only few teachers in Bangladesh who are expert in scholarly writing, but they don't have time to spend for others. As a result, young teachers and novice researchers are deprived of practical experience of scholarly writing. It is time for all of us to change the situation. 
In the developing countries, the Government has passed research budget in the parliament; which is very limited in comparison to the developed countries. Another problem may be mentioned in this regard that there is a huge shortage of expert researchers in any branch of knowledge; most of them have no practical experience in research field.

In my opinion, Scholarly writing in the Asian countries is more noticeable than African and Middle East countries. Poverty, hunger, racial and communal conflicts, and AIDS are the major crises in African countries. Most of the people of Africa are deprived of basic human needs. They have no capability to carry out a successful potential research project in different branches of science, arts, humanities, and commerce. The Government also cannot meet the demand of the young teachers and researcher scholars for their successful potential research project. Teachers are not professionally trained up in the field of research methodology. They need to be taken research training and to participate in the International Conference, Symposium, Workshop, and Mini talk at home and abroad. The major problem is that they have funding problem in Africa's educational institutions. The Government should take effective steps so that the young scholars and teachers can acquire research knowledge in different fields.

As for scholarly writing in the Middle East countries, the situation is almost same. Though some countries have plenty of natural resource and financial support, the Government doesn't want to spend finance for research project. In the Arabian Educational Institutions, there is a big demand of the English Language, but there is a huge shortage of qualitative and quantitative research among the teachers and researchers. Among Middle East Countries, Iran is on the triumph march in the research field, especially nuclear energy.

Anyway, the Governments as well as the conscious citizens of African, Asian, and Middle East Countries should come forward to take pragmatic measurements so that teachers and novice researchers can be motivated in scholarly writing. They should find out the potentiality of potential research project in order that the younger generation can be properly benefitted to carry out a successful research project.

Scholarly writing in the European countries is on the increase day by day. They provide ample opportunity for young teachers and researchers to carry out a successful research project; they provide scholarship, funding support and assistantships for the young research scholars; the Government of European countries have sufficient budgets in the field of research project; Another important thing may be mentioned in this regard, research scholars are devoted to conduct a scientific project, which maintains integrity, ethics, rules and instructions. Supervisors use plagiarism software checker to check scholar writing whether it is plagiarized or not. They maintain research integrity in any potential research project. The Educational Institutions of European countries are highly developed and polished in the field of research project. The potential research project of European countries is more scientific and authentic than Asian, African, Middle East countries.

Many teachers, students, and researchers of the developing countries have great expectations to European degrees; they have a notion that European degrees are more demandable and valuable than any other countries of the world. Those have brilliant result, academically are devoted to higher studies in Europe. The reason is that the research community, a program developed in consultation with industry provides researchers with a holistic approach to potential research training. The program covers topics, including-potential research integrity, networking, communication skills, and intercultural communication, creative writing skills, literary maturity, teamwork, resume writing, resilience, and emotional intelligence

In the light of Global Perspectives, scholarly writing inspires both young teachers and novice researchers for a 'yes' relation with the 21 st-century age. They spread core of ideas through the critical analysis and investigation of scholarly writing in the contexts of global significance. Global contexts as well as scholarly writing are on the basis of research skills of the young teachers and novice researchers. They can be able to foster research, thinking, and reasoning and communication skills by following a methodology, like-APA, MLA, or Chicago Manual Style with a view to finding out arguments and perspectives known as "Critical Planning. Collaborative skills" are developed through participation in a team project. The skills, which are received through the study of Global Perspectives and scholarly writing, inspire the young teachers and novice researchers to tackle the 
demands of 21 st-century scholarly writing and to make a successful and potential transition to study in higher studies at home and abroad.

\section{Significance OF THE STUdY}

Integrity or honesty is a noble quality in human life. Without this virtue, we cannot progress and go ahead. But now-a-days, there are many people living in the society as well as community, who don't try to realize the true meaning of integrity. For the time being, they may develop or have power and pelf, but when they will die or leave this earth forever, nobody will feel pity or weep for them. In this sense, we can remember a proverb: A man may live by his deeds, not by years. It means that our life is very transient, but our deed is long. We should have a due respect to honesty. To the end, integrity shall remain forever; but our life will demolish. Anyway, this study wants to signify some noble virtues when any research scholar decides to carry out a scholarly project, there must have research integrity in his writing. Otherwise, there would be no essence and value of the research project. Nobody will get benefit from his project. The project fails to meet the demand of the features and basic essence of research writing. Research scholar must acknowledge utterly from where he has collected his materials through following research methodology.

From the epistemological point of view, this study would like to show the young research scholars a right and honest path how he can be able to follow guidelines of scholarly writing. It aims to look at a bridge between a research scholar and a research supervisor in the light of research integrity. It also indicates that a research scholar must obtain basic qualities like a scientist to find out the potentiality and new aspects of research writing in the 21st - century age. Research scholar must have acquired philosophical and scientific dictum in carrying out a potential research project. He must continue to find out something new.

The aim of this project is to find out a philosophical and scientific truth in this sense that whenever a research scholar aims to investigate and explore scholarly project, this research project emphasizes upon the view that he should apply the theory of epistemology, maintaining research integrity. Research means to find out a true mystery of branches of knowledge, which anyone thinks and imagines, but he don't come to the final solution. For this adventurous task, he must work hard, must have meditation, dignity and honest aim to fulfill his target. Within the limited span of life, no research scholar can solve the complicated problem of research task alone.

From the global point of view, this research project would like to foster a new aspect of research integrity through which a young researcher can be able to invent a perfect potential project so that novice researchers can acquire fundamental truth of scholarly writing. A research project must have a universal appeal; it can show a new guideline for the young scholars when they hit upon a plan to start a potential project. Through this research project, the researcher wants to highlight how a novice researcher can be able to gain his maturity in carrying out a scholarly project.

\section{RECOMMENDATIONS AND CONCLUSION}

From the above the discussion, we can draw a concluding remark that in the study, the researcher has tried to highlight the prevailing problems of scholarly writing around the globe. Without research publication, young teachers and novice researchers cannot expect to go abroad for higher studies, to conduct a research project, to get academic promotion and salary increment, and to popularize research writing among their communities and circles. It is the duty and responsibility of all researchers to practice scientific research project. The government should not only come forward, but also increase the research budget to enhance the potentiality and innovative cornerstones of the potential research project in all branches of epistemology around the world.

Anyway, I strongly recommend the following points for the young teachers and research scholars:

To practice scholarly writing scientifically;

To get rid of plagiarized writing;

$>$ To maintain integrity and honesty while conducting a scientific research project;

$>$ Try to find out a new aspect of research methodology;

$>$ To inspire novice researchers in scholarly writing;

To have devoted to scholarly writing; 
To participate in the research related conference nationally and internationally;

To try to publish more and more articles in the renowned journals;

To investigate the problems and then try to solve them;

To carry out a scientific research project, researchers must bear in mind a famous wise saying, "Honesty is the best policy."

\section{REFERENCE}

[1] Steneck, N. H. (2007). ORI-Introduction to the Responsible Conduct of Research, Washington D.C. , U.S. Government Printing Office, p. 3.

\section{AUTHOR'S BIOGRAPHY}

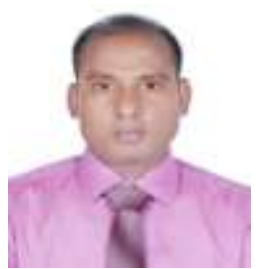

Mr. Hossain, did his BA (Hons) and MA in English Literature at The People's University, Bangladesh. He is an M. Phil Research Scholar in the Department of English at Jahangirnagar University. As an Assistant Professor, he is teaching English Literature and Language at IBAIS University. He also did serve as a Research Associate (Part-Time) at Uttara University, as a Lecturer of English at America Bangladesh University, BGIFT-Institute of Science \& Technology (BIST). He authored a book on Ibsen Studies. He has written 50 articles and published more than 40 articles in the International Scholarly Journals around the world. He is a reviewer and editorial board member of more than 70 International Scholarly Journals. He has presented 10 papers in the International Conferences in Bangladesh, UK, and India. He is a member of MLA, ISA, BSA, ACSE, ASTR, ESRA, AARE, EASE, ILA, TESOL, ASLE, MHRA, ALUS, MLPS, GRDS, ISDS, ISMTE, JDSA, MSA, DLS, GHS, WMSA, ATHE, IRFELE, AIRA, \& AHRA.

Citation: Mr. Hossain,. Research Integrity in Scholarly Writing: A Global Perspective. International Journal on Studies in English Language and Literature (IJSELL), vol 5, no. 11, 2017, pp. 14-27. doi: http://dx.doi.org/ 10.20431/2347-3134.0511003.

Copyright: () 2017 Authors. This is an open-access article distributed under the terms of the Creative Commons Attribution License, which permits unrestricted use, distribution, and reproduction in any medium, provided the original author and source are credited. 